09,14

\title{
Рассеяние света пористыми ориентированными пленками из полипропилена
}

\author{
(C) А.А. Зинчик ${ }^{1}$, И.С. Курындин ${ }^{2}$, Г.К. Ельяшевич 2 ף \\ ${ }^{1}$ Санкт-Петербургский национальный исследовательский университет \\ информационных технологий, механики и оптики, \\ Санкт-Петербург, Россия \\ ${ }^{2}$ Институт высокомолекулярных соединений РАН, \\ Санкт-Петербург, Россия \\ ฯ E-mail: elya@hq.macro.ru \\ (Поступила в Редакцию 29 июня 2016 г. \\ В окончательной редакции 26 августа 2016 г.)
}

Методом рассеяния лазерного излучения исследованы ориентированные пористые пленки из полипропилена с ламелярной кристаллической структурой. Установлена зависимость параметров картины рассеяния от степени ориентации пленки. Показано, что размеры центрального максимума картины рассеяния линейно зависят от степени растяжения пленок. Полученные результаты могут быть использованы при разработке методов оптического неразрушающего контроля полимерных материалов.

Работа выполнена при поддержке РФФИ (проект № 16-03-00265-а).

DOI: 10.21883/FTT.2017.03.44171.266

\section{1. Введение}

Материалы с пористой структурой обладают специфическими физическими свойствами. Для них характерны значительная диффузионная проницаемость, малое гидродинамическое сопротивление, способность к селективной фильтрации, высокие адсорбционные характеристики, малые звукопроводность и теплопроводность. Особое внимание среди этих материалов привлекают пористые пленки из полиолефинов, которые находят широкое применение в качестве фильтрационных материалов различного назначения, сепараторов в химических источниках тока, а также подложек для получения композиционных систем [1-4]. Одним из высокотехнологичных способов получения пористых пленок из полиолефинов - полиэтилена (ПЭ) и полипропилена (ПП) - является метод, основанный на экструзии их расплавов с последующим изометрическим отжигом, одноосным растяжением и термофиксацией [5,6]. На стадиях экструзии и изометрического отжига в пленках формируется ориентированная кристаллическая структура, состоящая из крупных ламелей (пластинчатых кристаллов), в которых молекулярные цепи вытянуты в направлении ориентации. Стадия порообразования осуществляется как процесс одноосного растяжения отожженных пленок, обладающих специфическим сочетанием механических свойств, а именно способностью к большим обратимым деформациям при высоком модуле упругости, характерном для ориентированных полимеров (так называемые ,жесткие эластики“). Одноосное растяжение жесткоэластических образцов приводит к раздвижению кристаллических ламелей и появлению между ними разрывов сплошности - пор.
При больших степенях растяжения в результате увеличения размеров и числа пор происходит их слияние и образование сквозных каналов: образец становится фильтрационной мембраной, проницаемой для жидкостей [7]. Стабильность образовавшейся пористой структуры достигается с помощью термической фиксации - выдерживания образцов в растянутом состоянии при повышенных температурах для снятия внутренних напряжений.

Экструдированные ПП-пленки характеризуются высокими коэффициентами пропускания света в видимой части спектра, особенно в ее длинноволновой области [8]. Коэффициент светопропускания на длине волны $600 \mathrm{~nm}$ составляет 84\% при толщине пленки $22 \mu \mathrm{m}$. При образовании пор в процессе растяжения прозрачная отожженная пленка становится молочно-белой, непрозрачной в видимом свете вследствие сильного оптического рассеяния на стенках пор.

Для полимеров при прохождении света через образец чаще всего наблюдается рассеяние как поверхностью, так и неоднородностями в объеме материала, в том числе в направлении, обратном направлению падающего света. Причиной недостаточной прозрачности большинства аморфно-кристаллических полимеров является рассеяние света надмолекулярными образованиями (на границе между кристаллической и аморфной частями) $[9,10]$. Мутность полимера характеризуют коэффициентами либо направленного, либо рассеянного пропускания [11]. Рассеяние света в полипропилене связано с его оптической неоднородностью, обусловленной разницей плотностей аморфной и кристаллической фаз $\left(0.850\right.$ и $0.936 \mathrm{~g} / \mathrm{cm}^{3}$ соответственно). В работах $[12,13]$ было показано, что интенсивность рассеянного света 
снижается с уменьшением степени кристалличности полимера.

Исследования оптического рассеяния пористыми полимерами с использованием лазерных источников были начаты в 70-х годах прошлого века $[11,12]$ и получили развитие в работах [14-17]. В настоящей работе получены картины рассеяния лазерного излучения на пористых полипропиленовых пленках с различной степенью ориентации, проведен их анализ и выполнены расчеты, которые позволили интерпретировать экспериментальные данные в рамках модели двумерной дифракции.

\section{2. Объекты и методы исследования}

Для получения пористых пленок использовались гранулы изотактического ПП промышленной марки PPG 1035 (Ставролен, Россия) с молекулярной массой $M_{w}=380000$, полидисперсностью $M_{w} / M_{n}=4-5$ и температурой плавления $T_{m}=172^{\circ} \mathrm{C}$. Формование пленок проводилось на лабораторном экструдере фирмы „SCAMIA“ (Франция) при скорости приема пленки, значительно превышающей скорость выхода расплава из фильеры. Степень ориентации экструдированных образцов характеризовалась кратностью фильерной вытяжки $\lambda$, которая определялась как отношение скорости приема пленки к скорости подачи расплава.

Отжиг экструдированных пленок осуществлялся в условиях фиксации концов образца в течение часа при температуре $170^{\circ} \mathrm{C}$.

Одноосное растяжение ПП-пленок после отжига (стадия порообразования) выполнялось при комнатной температуре.

Для предотвращения усадки пленок после снятия растягивающего напряжения проводилась их термическая стабилизация выдерживанием в изометрических условиях в течение часа при температуре $130^{\circ} \mathrm{C}$.

Для изучения рассеяния когерентного излучения была собрана установка, аналогичная рассмотренной в работе [18]. Установка (рис. 1) включала в себя источник излучения, систему формирования пучка и устройство регистрации, соединенное с персональным компьютером. Источником излучения 1 служил гелий-неоновый лазер с длиной волны $632.8 \mathrm{~nm}$. Блок 2 из двух нейтральных светофильтров НС-8 и НС-10, размещаемых последовательно, использовался соответственно для грубой и точной регулировки интенсивности падающего излучения, что предохраняет поверхность CCD-матрицы от повреждений лазерным излучением. Поляризатор 3 обеспечивает минимальные размеры пучка на CCD-матрице. Оправа поляризатора позволяет вращать его в диапазоне углов от 0 до $360^{\circ}$ с точностью позиционирования до $1^{\circ}$. Диафрагма 4 с отверстием диаметром $0.7 \mathrm{~mm}$ ограничивает пропускание только основной моды лазерного пучка $\mathrm{TEM}_{00}$.

Положительная линза 5 с фокусным расстоянием $150 \mathrm{~mm}$ обеспечивает фокусировку излучения на устрой-

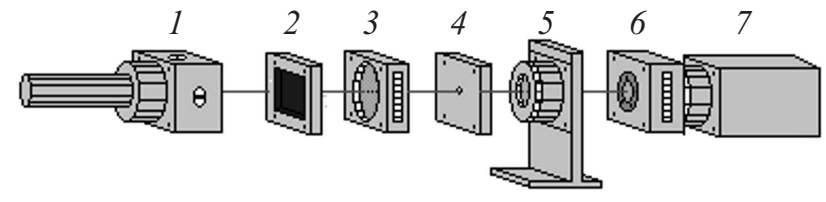

Рис. 1. Схема установки для исследования рассеяния света с лазерным источником излучения. Обозначения приведены с тексте.

стве регистрации при отсутствии образца. Оправа 6 с образцом размещается вплотную к торцу камеры для установления минимального расстояния до CCD-матрицы, что позволяет регистрировать рассеяние на больших углах. Такая регистрация необходима вследствие того, что размеры неоднородностей полимерных пленочных мембран составляют единицы микрометров, и соответственно углы рассеяния излучения видимого диапазона будут около $20^{\circ}$. Оправа допускает вращение образца вокруг оптической оси установки в диапазоне от 0 до $360^{\circ}$ с минимальным шагом $1^{\circ}$.

Для регистрации дифракционной картины использовалась видеокамера 7 c $\mathrm{CCD}$-матрицей и автоматической подстройкой чувствительности. Размер CCD-матрицы видеокамеры $23.6 \times 15.6 \mathrm{~mm}$, разрешение $3696 \times 2448$ пикселей. Размер пикселя составлял $6 \mu \mathrm{m}$. Для увеличения углового поля зрения с камеры был снят объектив. Полученные из различных частей образцов картины рассеяния усреднялись с целью сглаживания спекл-структуры.

\section{3. Результаты и обсуждение}

Изучение рассеяния света проводилось на двух сериях пленок, экструдированных при кратностях фильерной вытяжки $\lambda=44$ и 78. В каждой серии варьировалась степень одноосного растяжения образцов $\varepsilon$ от 50 до $200 \%$. Величина деформационных воздействий на стадиях экструзии и одноосного растяжения в процессе порообразования определяет степень ориентации пористых образцов. Результаты влияния одноосного растяжения на картину рассеяния света представлены на рис. 2.

Из рисунка видно, что увеличение $\varepsilon$ приводит к заметному изменению центрального максимума и всей картины рассеяния. Пористая пленка, полученная при $\varepsilon=50 \%$ (рис. 2,a), обладает наименьшей в данной серии образцов степенью ориентации, и картина рассеяния для нее имеет вид, характерный для изотропных полимерных объектов. При увеличении степени ориентации картина рассеяния становится резко неоднородной, а именно появляется центральный максимум и боковые „крылья“. Картина приобретает вид „бабочки“, наблюдавшийся ранее для ориентированных пористых ПЭ-пленок [19]. По мере роста степени растяжения происходит деформация центрального максимума увеличение анизометрии, проявляющееся в его сжатии 


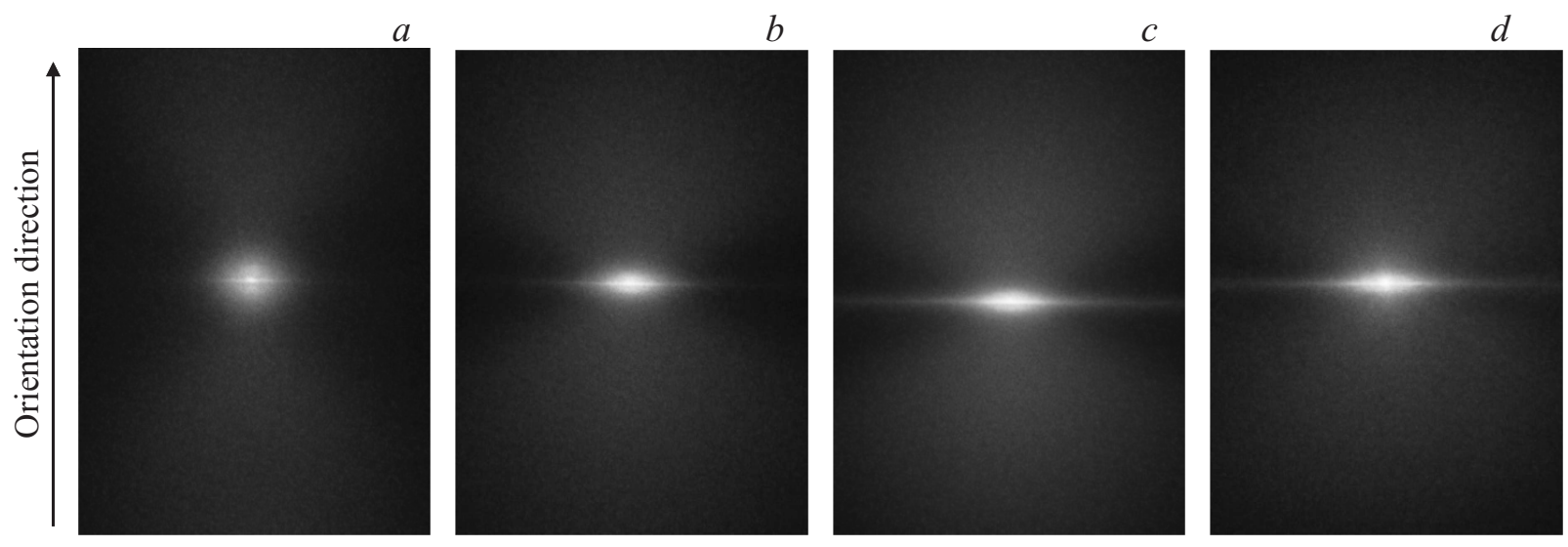

Рис. 2. Усредненные изображения картин рассеяния света для пористых ПП-пленок, полученных при $\lambda=78$ и степенях одноосного растяжения $\varepsilon=50(a), 100(b), 150(c)$ и $200 \%(d)$.

в направлении ориентации и растяжении в перпендикулярном направлении (рис. $2, b-d$ ).

Чтобы проанализировать изменения картин рассеяния, были построены сечения их центральной области и по ним определены размеры центрального максимума. Как видно из рис. 3, размеры центрального максимума картины рассеяния в направлении ориентации пленок $\left(D_{1}\right)$ и в перпендикулярном направлении $\left(D_{2}\right)$ для образцов, полученных при $\lambda=44$, больше, чем для
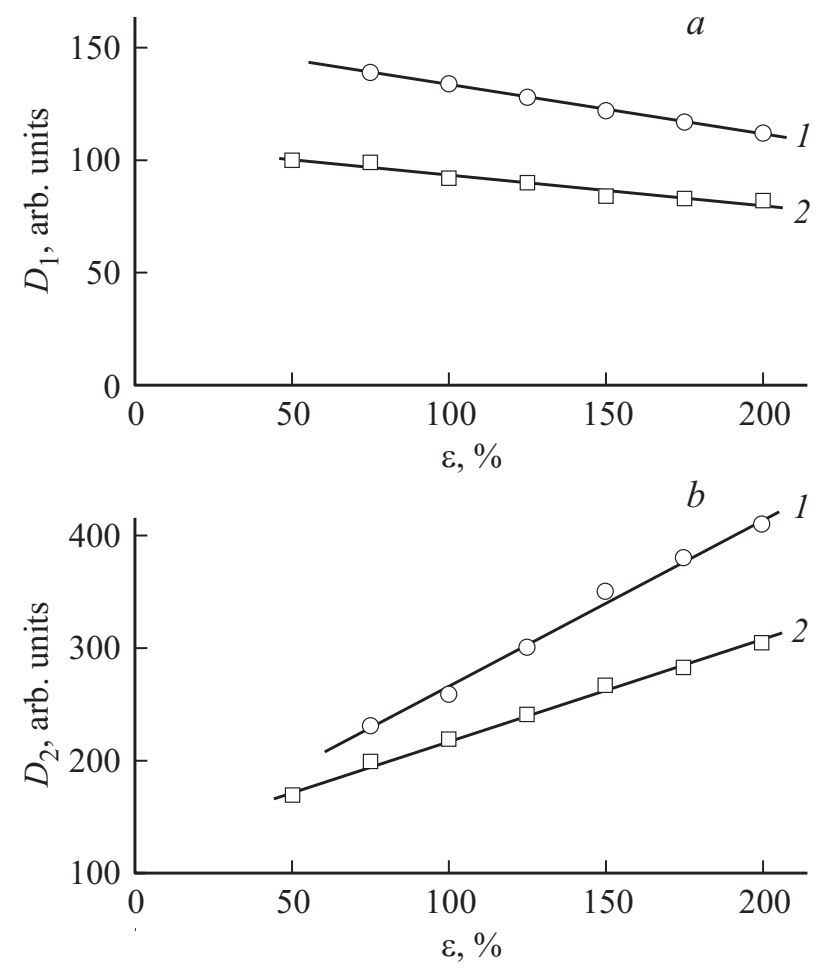

Рис. 3. Зависимость размеров центрального максимума картины рассеяния в направлении ориентации $D_{1}(a)$ и в перпендикулярном направлении $D_{2}(b)$ от $\varepsilon$ для пористых ПП-пленок, полученных при кратностях фильерной вытяжки 44 (1) и 78 (2).

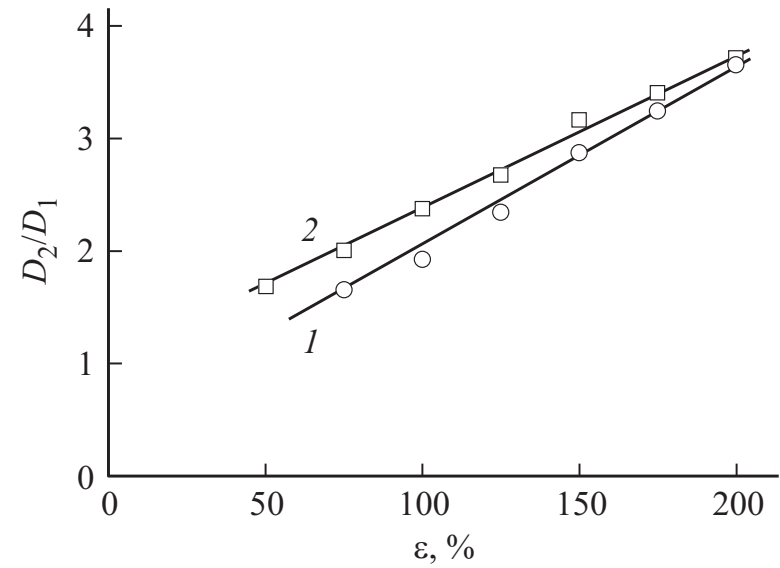

Рис. 4. Зависимость отношения $D_{2} / D_{1}$ от $\varepsilon$ для пористых ПП-пленок, полученных при кратностях фильерной вытяжки 44 (1) и 78 (2).

пленок, сформованных при $\lambda=78$. Это объясняется возрастанием их степени ориентации с кратностью фильерной вытяжки, что приводит к росту светопропускания и соответственно снижению интенсивности рассеяния.

С увеличением степени одноосного растяжения $\varepsilon$ для обоих образцов наблюдается закономерное сужение центрального максимума в направлении ориентации и его рост в перпендикулярном направлении. Эти изменения представлены на рис. 4 как отношение $D_{2} / D_{1}$ и отражают увеличение анизотропии образцов с ростом $\varepsilon$. Как видно из рис. 4, пористые пленки, полученные при $\lambda=78$, характеризуются более высокими величинами $D_{2} / D_{1}$, чем образцы, сформованные при $\lambda=44$. Однако угол наклона зависимости уменышается с ростом кратности фильерной вытяжки. Это свидетельствует о том, что процессы ориентации при одноосном растяжении происходят эффективнее для пленок, более слабо ориентированных при экструзии. При $\varepsilon=200 \%$ степени анизотропии обоих образцов становятся одинаковыми. 


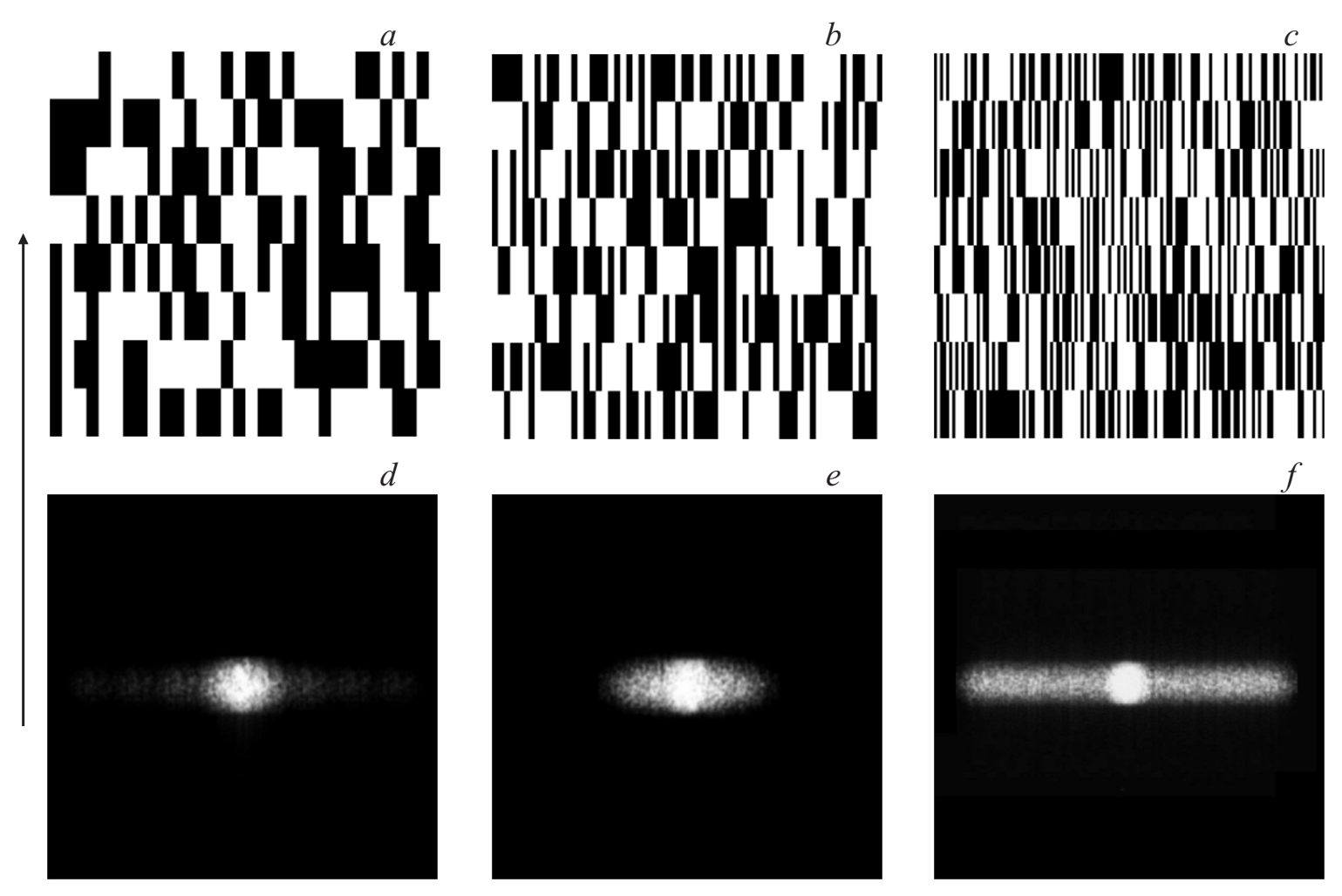

Рис. 5. Модели решеток с переменной шириной штриха, использовавшиеся при моделировании $(a-c)$, и соответствующие им расчетные картины дифракции $(d-f)$. Стрелкой обозначено условное направление ориентации. Минимальный размер штриха составляет $20(a), 10(b)$ и $5 \mu \mathrm{m}(c)$.

Эти результаты согласуются с данными малоуглового рентгеновского рассеяния [7], которые показывают рост степени ориентации пористых пленок полиолефинов с увеличением растягивающих воздействий при формировании их структуры.

Дифракция оптического лазерного излучения на ориентированных полимерных пористых пленках может быть интерпретирована в рамках на модели дифракционной решетки с переменным расстоянием между штрихами. Дифракция на такой решетке дает растянутый перпендикулярно направлению штрихов центральный максимум, аналогичный экспериментально наблюдаемому (рис. 2) центральному элементу картины рассеяния света на пористой ПП-пленке.

Для подтверждения рассматриваемой модели было проведено моделирование рассеяния света с помощью набора дифракционных решеток с переменным расстоянием между штрихами. В качестве среды моделирования использовали программный пакет VirtualLab 5.0 производства LightTrans GmbH, а в качестве объекта модели решеток, оцифрованные с шагом дискретизации $1 \mu \mathrm{m}$ на один пиксель изображения (рис. $5, a-c$ ). Модели решеток, представленные на рис. 5, различаются шириной штриха. Высота штриха составляла $100 \mu \mathrm{m}$. Минимальная ширина штриха варьировалась в диапазоне от 5 до $20 \mu \mathrm{m}$. Чтобы учесть отсутствие прямолинейных участков полимерных цепей, использовалось несколько решеток, размещенных в одной плоскости (рис. 5). Полученное изображение рассматривалось как амплитудный объект, прозрачный в светлых областях картинки и непрозрачный в темных. Моделирование проводили по рассеянию излучения с плоским волновым фронтом и длиной волны $633 \mathrm{~nm}$. С использованием приближения Фраунгофера были получены распределения интенсивности в плоскости изображения. Результаты моделирования демонстрируют растянутый центр, соответствующий центральной области экспериментальной картины рассеяния (рис. $5, d-f)$.

Подтверждение используемой модели дают результаты микроскопического исследования ПП-пленки. На рис. 6 показаны фотографии, полученные с помощью оптического микроскопа с видеокамерой в проходящем свете. На этих фотографиях отчетливо видны детали структуры, формирующие вертикальные элементы решетки с характерными размерами от 5 до $100 \mu \mathrm{m}$. Рассеяние света на этих элементах дает центральный максимум, вытянутый в направлении, перпендикулярном направлению растяжения пленки. Из рис. 6 видно также, что при увеличении степени растяжения уменьшаются толщина деталей структуры и расстояние между ними, что приводит к растяжению центрального максимума картины рассеяния в направлении, перпендикулярном направлению растяжения пленки. 

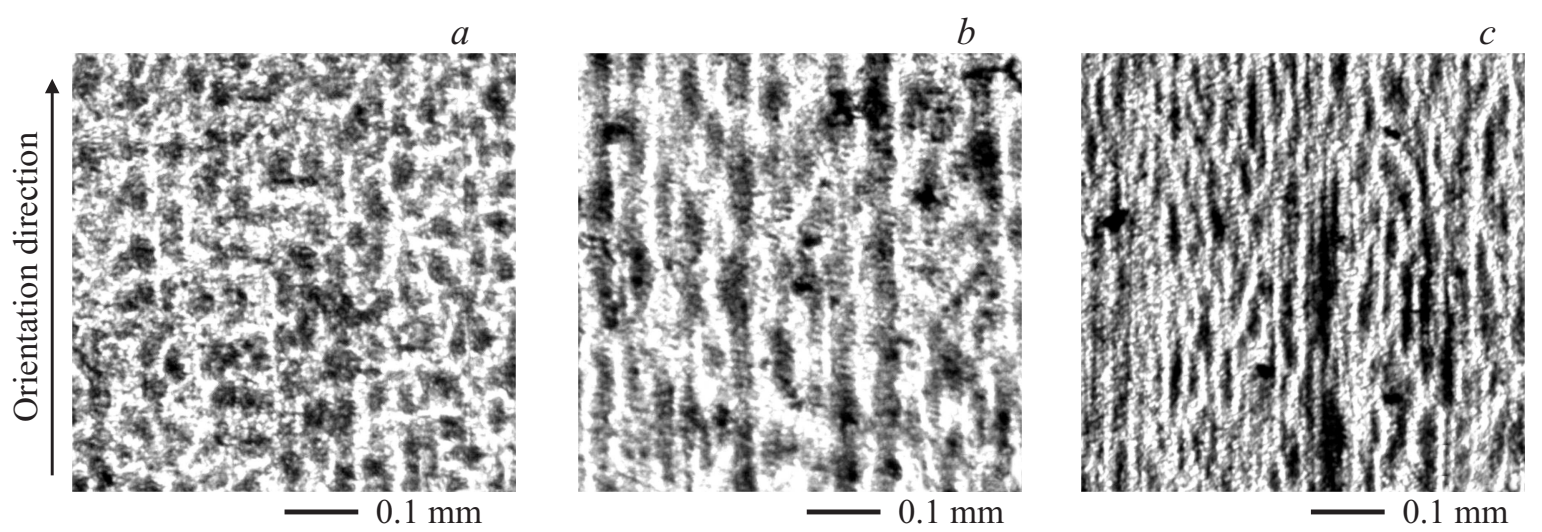

Рис. 6. Оптические фотографии пористых ПП-пленок, полученных при $\lambda=78$ и степенях одноосного растяжения $\varepsilon=50(a)$, $100($ b) и $200 \%$ (c).

Чтобы проанализировать изменения модельных картин рассеяния, были построены сечения их центральной области и по ним определены размеры центрального максимума. Как видно из рис. 7, отношение размеров центрального максимума картины рассеяния в направлении ориентации пленок и в перпендикулярном направлении, рассчитанное с использвоанием модели $\left(D_{2 M} / D_{1 M}\right)$, растет с уменьшением размера штриха $(d)$. Зависимость оказывается обратной по сравнению с приведенной на рис. 4 , поскольку увеличение степени одноосного растяжения $\varepsilon$ ведет к уменьшению толщины элементов структуры ПП-пленки. Сопоставление рис. 4 и 7 показывает, что экспериментальные данные находятся в согласии с результатами анализа в рамках рассматриваемой модели. Так, увеличение $\varepsilon$ в 2 раза дает такое же изменение отношения $D_{2} / D_{1}$ на экспериментальной картине рассеяния (рис. 4), как и изменение аналогичного отношения $D_{2 M} / D_{1 M}$ при уменьшении во столько же раз толщины элементов решетки на модельных картинах (рис. 7).

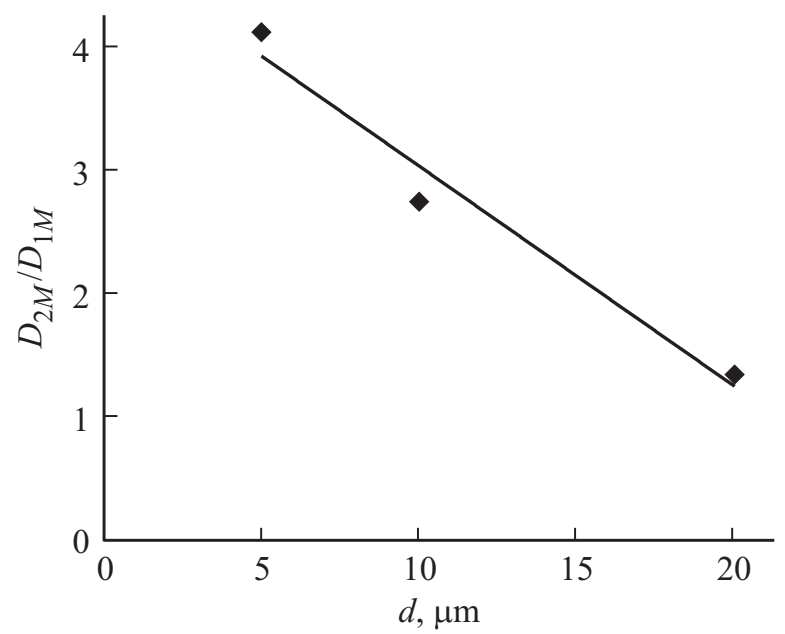

Рис. 7. Зависимость отношения размеров центрального максимума в направлении ориентации и в перпендикулярном направлении $\left(D_{2 M} / D_{1 M}\right)$ на модельной картине рассеяния от минимального размера штриха решетки $(d)$.

\section{4. Заключение}

В работе исследовано рассеяние света ориентированными пористыми пленками из полипропилена и проведен анализ полученных картин рассеяния. Экструдированная и отожженная пленки имеют однородную структуру и не показывают специфической картины рассеяния. При последующем одноосном растяжении образец становится неоднородным вследствие формирования пористой структуры и появления границы раздела по стенкам пор. Неоднородность плотности фаз в пористых образцах является причиной рассеяния света на них, a характерные черты картины рассеяния зависят от степени ориентации пленок.

Предложена модель дифракционной решетки с переменным расстоянием между штрихами, которая описывает картину рассеяния света исследуемыми пористыми образцами. Изменения центрального максимума в процессе растяжения убедительно объясняются моделью, рассматривающей структуру полипропиленовой пленки как решетку с переменным расстоянием между штрихами. Наличие боковых крыльев не объясняется этой моделью, но можно предположить, что световое излучение, проходя через систему пор, рассеивается в боковых направлениях. Этот вопрос требует дальнейшего изучения.

\section{Список литературы}

[1] M. Mulder. Basic principles of membrane technology. Kluwer Academic Publ., Dordrecht (1991). 363 p.

[2] R.E. Kesting. Synthetic polymer membranes - a structural perspective. John Wiley \& Sons, Chichester-N.Y. (1985). $348 \mathrm{p}$.

[3] S.S. Zhang. J. Power Sources 164, 351 (2007).

[4] A.Yu. Bobrovsky, V.P. Shibaev, G.K. Elyashevitch, E.Yu. Rosova, A. Shimkin, V. Shirinyan, A. Bubnov, M. Kaspar, V. Hamplova, M. Glogarova. Liquid Cryst. 35, 533 (2008).

[5] Г.К. Ельяшевич, Е.Ю. Розова, Е.А. Карпов. Патент РФ № 2140936 (1997). 
[6] Г.К. Ельяшевич, И.С. Курындин, В.К. Лаврентьев, А.Ю. Бобровский, V. Bukošek. ФТТ 54, 1787 (2012).

[7] И.С. Курындин, В.К. Лаврентьев, V. Bukošek, Г.К. Ельяшевич. Высокомолекуляр. соединения А 57, 497 (2015).

[8] В.Н. Серова. Оптические и другие материалы на основе прозрачных полимеров. КГТУ, Казань (2010). 540 с.

[9] В.Г. Рупышев, Е.И. Кривченко. Междунар. новости мира пластмасс 6, 41 (2006).

[10] Т.А. Сперанская, Л.И. Тарутина. Оптические свойства полимеров. Химия, Л. (1976). 136 с.

[11] J. Dechant, R. Danz, W. Kimmer, R. Schmolke. Ultrarotspektroskopische Untersuchungen an Polymeren. AkademieVerlag, Berlin (1972). 516 s. [И. Дехант, Р. Данц, В. Киммер, Р. Шмольке. Инфракрасная спектроскопия полимеров. Пер. с нем. Химия, М. (1976). 472 с.]

[12] А.И. Колядин, Т.И. Мухина, Э.И. Шепурев. Опт.-мех. пром-ть 47, 28 (1980).

[13] P.H. Chen, Y.F. Yang, D.-K. Lee, Y.-F. Lin, H.-H. Wang, H.-B. Tsai, R.-S. Tsai. Adv. Polym. Technol. 26, 33 (2007).

[14] Г.К. Ельяшевич, А.А. Зинчик, А.П. Мельничук, А.В. Смирнов, С.К. Стафеев, Б.А. Федоров. Изв. вузов. Приборостроение 41, 72 (1998).

[15] Г.К. Ельяшевич, А.Г. Козлов, А.П. Ковшик, Е.И. Рюмцев. Опт. журн. 65, 51 (1998).

[16] Yu.A. Vlasov, X.Z. Bo, J.C. Sturm, D.J. Norris. Nature 414, 289 (2001)

[17] W. Schärtl. Light scattering from polymer solutions and nanoparticle dispersions. Springer, Berlin. (2007). 191 p.

[18] A.A. Zinchik, I.S. Kuryndin, K.V. Ezhova, G.K. Elyashevich. Proc. SPIE. 9890, 989016 (2016).

[19] A.A. Zinchik, S.K. Stafeev, B.A. Fedorov, G.K. Elyashevich, A.G. Kozlov. Proc. SPIE. 3482, 867 (1998). 